\title{
STUDI RUGI DAYA SISTEM KELISTRIKAN BALI AKIBAT PERUBAHAN KAPASITAS PEMBANGKITAN DI PESANGGARAN
}

\author{
I P. A. Edi Pramana ${ }^{1}$, W. G. Ariastina ${ }^{2}$, I W. Sukerayasa ${ }^{3}$
}

\begin{abstract}
In the years of 2014 until 2015 Pesangaran plant capacity undergo changes due to the expiration of employment contract lease diesel units and also the addition of new plant unit of 200 MW PLTMG. An increase or reduction in plant capacity of electrical system Bali will lead to significant changes to the load flow, power losses and energy losses in the circuit of Bali electrical Transmission system. Load flow analysis and power losses in Bali electricity system is simulated in five scenarios. Scenario 1 for the conditions of existing in 2014, scenario 2 is currently experiencing a reduction Pesanggaran plant capacity in December 2014, scenario 3 is currently experiencing Pesanggaran plant capacity additions in 2015 by using a peak load of 2014, scenario 4 is the scenario 3 with using predicted peak load in 2015, and scenario 5 is the scenario 4 with assuming the Celukan Bawang plant operates at $130 \mathrm{MW}$. Based on the results obtained by analysis, scenario 2 has the most power and energy loss about 46.34 MW and 300.39 GWh. For the loss of power and energy Bali electrical systems after Pesanggaran plants changes in 2015 are $38.57 \mathrm{MW}$ and $250.05 \mathrm{GWh}$
\end{abstract}

Intisari - Pada tahun 2014-2015 kapasitas pembangkit Pesangaran akan mengalami perubahan karena berakhirnya kontrak kerja unit pembangkit sewa PLTD dan juga penambahan unit pembangkit baru PLTMG 200 MW. Peningkatan maupun pengurangan kapasitas pembangkit pada sistem kelistrikan Bali akan menimbulkan perubahanperubahan yang signifikan terhadap aliran daya, rugi daya dan rugi energi pada saluran transmisi sistem kelistrikan Bali. Analisis aliran daya dan rugi daya sistem kelistrikan Bali disimulasikan dalam lima skenario.

\footnotetext{
1 Mahasiswa, Teknik Elektro dan Komputer Universitas Udayana, Kampus Bukit Jimbaran, Badung Bali. 80361, Tel. 0361703315 fax:0361703315; e-mail: agusedix@gmail.com

${ }^{2}$ Dosen Teknik Elektro dan Komputer Universitas Udayana, Kampus Bukit Jimbaran, Badung Bali. 80361, Tel. 0361703315 fax:0361703315; e-mail:w_ariastina@yahoo.com

${ }^{3}$ Dosen,Teknik Elektro dan Komputer Universitas Udayana, Kampus Bukit Jimbaran, Badung Bali. 80361, Tel. 0361703315 fax:0361703315; e-mail: sukerayasa@unud.ac.id
}

.Skenario 1 saat kondisi existing 2014, skenario 2 saat pembangkit pesanggaran mengalami pengurangan kapasitas Desember 2014, skenario 3 saat pembangkit pesanggaran mengalami penambahan kapasitas tahun 2015 dengan menggunakan beban puncak 2014, skenario 4 yaitu skenario 3 dengan menggunakan beban puncak prediksi tahun 2015, dan skenario 5 yaitu skenario 4 dengan asumsi PLTU Celukan Bawang beroperasi sebesar $130 \mathrm{MW}$ pada tahun 2015. Berdasarkan hasil analisis pada skenario $1 \mathrm{~s} / \mathrm{d} 5$ diperoleh skenario 2 memiliki rugi daya dan energi terbesar yaitu 46,34 MW dan 300,39 GWh. Untuk rugi daya dan energi sistem kelistrikan Bali setelah perubahan pembangkit Pesanggaran serta PLTU Celukan Bawang beroperasi pada tahun 2015 sesuai skenario 5 adalah sebesar 38,57 MW dan 250,05 GWh

Kata kunci: Pembangkit, aliran daya, skenario, susut daya, susut energi.

\section{PENDAHULUAN}

Penambahan dan pengurangan kapasitas pembangkitan di sistem Bali sering terjadi dengan rentang waktu yang lama, dikarenakan kebutuhan energi listrik yang terus meningkat, life time peralatan yang sudah berkurang, peremajaan peralatan maupun kontrak kerja yang berakhir

Pada tahun 2014-2015 kapasitas pembangkit di Pesanggaran akan mengalami perubahan dimana disebabkan oleh berakhirnya kontrak kerja beberapa pembangkit sewa dan masuknya pembangkit dari PLN. Peningkatan maupun pengurangan kapasitas pembangkit ke dalam sistem yang telah ada akan berdampak pada rugi-rugi daya pada saluran transmisi, arus hubung singkat, keandalan, dan juga kestabilan sistem kelistrikan Bali.

Dari permasalahan yang telah diuraikan tersebut, maka penelitian ini akan menganalisis aliran daya, rugi daya serta rugi energi sistem kelistrikan Bali dengan 5 skenario. Skenario 1 saat kondisi existing 2014, skenario 2 saat pembangkit pesanggaran mengalami pengurangan kapasitas Desember 2014, skenario 3 saat pembangkit pesanggaran mengalami penambahan kapasitas tahun 2015 dengan menggunakan beban puncak 2014, skenario 4 yaitu skenario 3 dengan menggunakan beban puncak prediksi tahun 2015, dan skenario 5 yaitu skenario 4 dengan asumsi PLTU Celukan Bawang beroperasi sebesar 130 MW pada tahun 2015. 
Menggunakan metode Newton Raphson dengan bantuan program Powerflow Simulator.

\section{ANALISIS ALIRAN DAYA}

Studi aliran daya adalah studi yang dilakukan untuk mendapatkan informasi mengenai aliran daya atau tegangan sistem dalam kondisi operasi tunak. Informasi ini sangat dibutuhkan guna mengevaluasi unjuk kerja sistem tenaga dan menganalisa kondisi pembangkitan maupun pembebanan. Analisa ini juga memerlukan informasi aliran daya dalam kondisi normal maupun darurat [1]. Studi aliran daya merupakan penentuan atau perhitungan tegangan, arus, daya aktif maupun daya reaktif yang terdapat pada berbagai titik jaringan listrik pada keadaan pengoperasian normal, baik yang sedang berjalan maupun yang diharapkan akan terjadi di masa yang akan datang [2]. Adapun tujuan dari studi analisa aliran daya antara lain [3]:

a. Untuk mengetahui tegangan-tegangan pada setiap bus yang ada dalam sistem, baik magnitude maupun sudut fasa tegangan.

b. Untuk mengetahui daya aktif dan daya reaktif yang mengalir dalam setiap saluran yang adadalam sistem.

c. Untuk mengetahui kondisi dari semua peralatan, apakah memenuhi batas-batas yang ditentukan untuk menyalurkan daya listrik yang diinginkan.

d. Untuk memperoleh kondisi mula pada perencanaan sistem yang baru.

e. Untuk memperoleh kondisi awal untuk studi studi selanjutnya seperti : studi hubung singkat, stabilitas, dan pembebanan ekonomis.

\subsection{Metode Newton-Raphson}

Pada dasarnya metode Newton Raphson adalah metode Gauss-Seidel yang disempurnakan, dimana metode ini dapat mengatasi kelemahan dari metode Gauss-Seidel antara lain dalam hal ketelitian dan jumlah iterasi. Persamaan daya adalah [2]

$\mathrm{P}_{\mathrm{i}}=\sum_{j=1}^{n}\left|V_{i}\right| V_{j} \quad Y_{i j} \cos \left(\theta_{i j}-\delta_{i}+\delta_{j}\right)$

$Q_{i}=-\sum_{j=1}^{n}\left|V_{i}\right| V_{j} Y_{i j} \sin \theta_{i j}-\delta_{i}+\delta_{j}$

\subsection{Analisis Rugi Daya}

Rugi daya dipengaruhi oleh dua hal penting yaitu arus beban dan tahanan penghantar. Untuk persamaan rugi daya dapat diuraikan sebagai berikut [3] :

Rugi daya nyata :

MW ujung kirim-MW ujung terima MW ujung kirim $\mathrm{x} 100 \%$

\subsection{Analisis Rugi Energi}

Analisis perhitungan rugi energi mempertimbangkan parameter rugi tembaga dan rugi kuadrat beban. Rugi tembaga atau rugi-rugi lainnya berbanding lurus dengan kuadrat beban, ini berarti semakin bertambah bebannya maka semakin besar rugi-rugi tembaga yang terjadi.

Rugi Energi $=$
Rugi daya beban puncak x loss factor x 8760

Dimana : 8760 merupakan jumlah jam dari periode tersebut (satu tahun).

\subsubsection{Loss Factor}

Loss factor merupakan rugi-rugi sebagai fungsi waktu, berubah sesuai dengan fungsi dari waktu kuadrat. Oleh karena itu, faktor rugi-rugi ini tidak dapat ditentukan langsung dari faktor beban. Berdasarkan pengalaman dan percobaan yang dilakukan oleh Buller dan Woodrow dengan menganalisa ratusan grafik diperoleh persamaan empiris sebagai berikut [4] :

$$
F_{L S}=0.3 F_{L D}+0.7 F_{L D}^{2}
$$

\subsubsection{Load Factor}

Faktor beban atau Load factor didefinisikan sebagai perbandingan antara beban rata-rata dengan beban puncak yang diukur untuk suatu periode waktu tertentu.

$$
L_{f}=\frac{B_{r}(\text { beban rata rata })}{\left.\mathrm{B}_{\mathrm{p}} \text { (beban puncak }\right)}
$$

\subsubsection{Beban Rata-Rata}

Beban rata-rata $(\mathrm{Br})$ didefinisikan sebagai perbandingan antara energi yang terpakai dengan waktu pada periode tertentu, atau dapat dituliskan menurut persamaan periode 1 hari :

$$
B_{r}=\frac{k \text { Wh yang terpakai selama } 1 \text { hari }}{24 \mathrm{jam}} \ldots \ldots \ldots \ldots \ldots . . . .
$$

\section{METODE}

Dalam penelitian ini menggunakan prediksi beban puncak sistem kelistrikan Bali tahun 2015 sesuai RUPTL tahun 20132022. Parameter data antara lain single line diagram, data penghantar $150 \mathrm{kV}$, data pembangkit sistem Bali, data pembebanan pada 15 Gardu Induk tahun 2014-2015, data kapasitor pada Gardu Induk sistem Bali, dan RUPTL PT PLN (Persero) 2013-2022.

Simulasi aliran daya dilakukan dengan bantuan software Etap Powerstation. Selanjutnya hasil aliran daya, rugi daya, dan energi pada skenario $1 \mathrm{~s} / \mathrm{d} 5$ dianalisis dan dibandingkan untuk mengetahui dampak sebelum dan sesudah perubahan kapasitas pembangkitan di Pesanggaran.

\section{PEMBaHASAN}

\subsection{Gambaran Umum Sistem Kelistrikan di Bali}

Sistem tenaga listrik $150 \mathrm{kV}$ di Bali mempunyai jaringan transmisi yang terbentang sepanjang $730 \mathrm{~km}$ yang terdiri dari 33 saluran dengan 15 Gardu Induk. Single line diagram sistem kelistrikan Bali dapat dilihat pada gambar 1. 


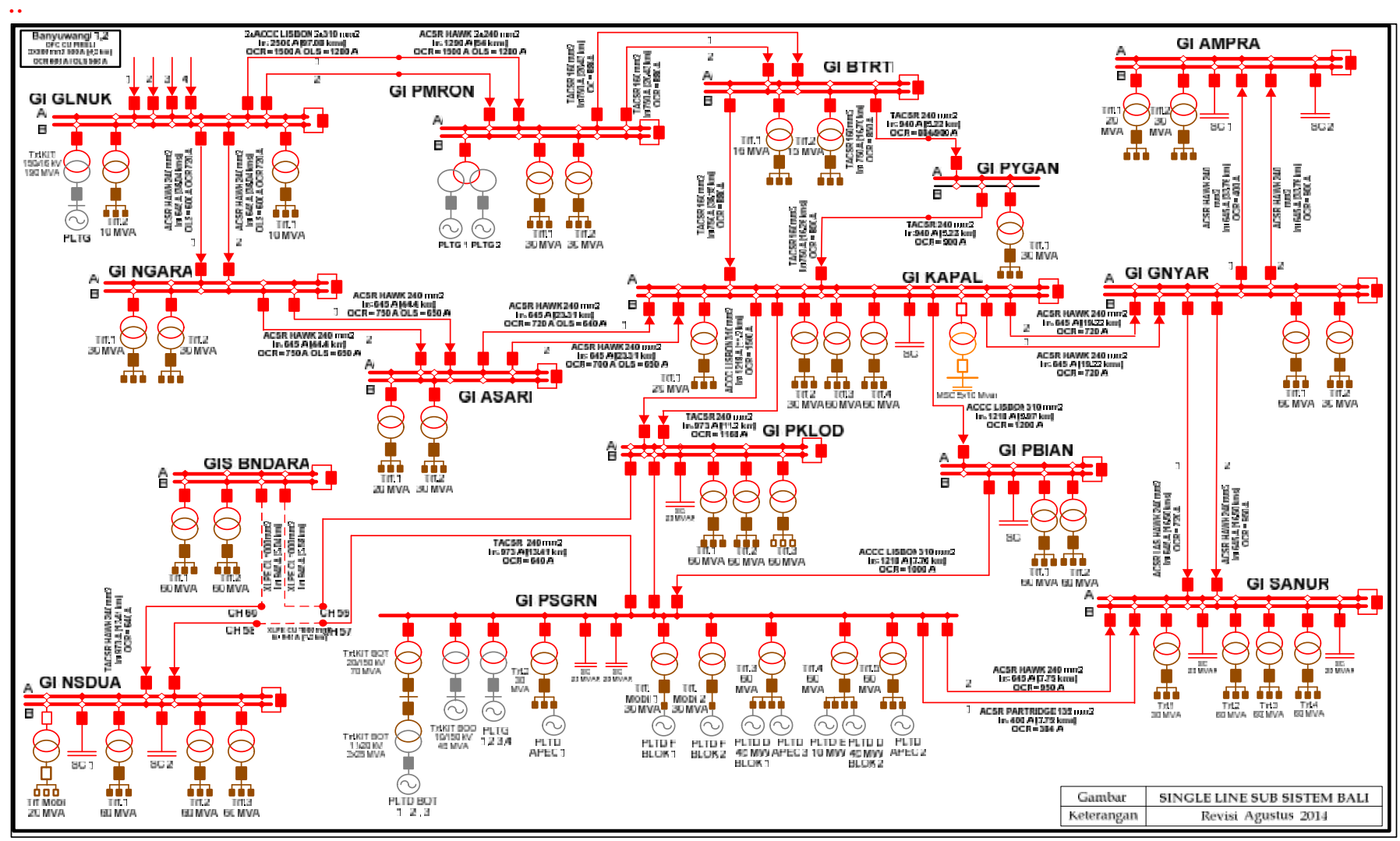

Gambar 1. Single Line Diagram Jaringan Transmisi 150 kV Bali

\subsection{Rencana Perubahan Kapasitas Pembangkitan di Pesanggaran}

Pada tahun 2014-2015 pembangkit sewa yang ada di Pesanggaran akan keluar diantaranya PLTD APEC, Sewatama, dan Cogindo total sebesar 140 MW pada bulan Desember 2014, serta PLTD BOO 30 MW pada bulan Februari 2015. Sedangkan pembangkit dari pihak PLN yang akan masuk yaitu PLTMG (Pusat Listrik Tenaga Mesin Gas) sebesar 200 MW di Pesanggaran secara bertahap. Tahap pertama $50 \mathrm{MW}$ Desember 2014, dan sisanya 150 MW pada tahun 2015 (PT Indonesia Power-UBPOH Bali, 2014).

\subsection{Hasil Analisis Aliran Daya dan Rugi Daya Skenario 1}

Aliran daya tahun 2014 dilakukan pada 15 bus di sistem kelistrikan Bali dengan menggunakan 4 bus sebagai sumber pembangkitan yaitu bus Pesanggaran, Pemaron dan Gilimanuk menggunakan mode voltage control sedangkan bus Banyuwangi menggunakan mode swing. Pembangkitan di Pesanggaran pada skenario 1 berkapasitas total sebesar 337,5 MW

Tabel 1. Rangkuman Hasil Analisis Aliran Daya dan Rugi Daya Skenario 1

\begin{tabular}{|c|l|l|l|}
\hline No & \multicolumn{1}{|c|}{ Uraian } & Nilai & Keterangan \\
\hline \multirow{2}{*}{1} & $\begin{array}{l}\text { Pembangkitan } \\
\text { Bali }\end{array}$ & $\begin{array}{l}547,50 \\
\text { MW }\end{array}$ & \\
\hline
\end{tabular}

\begin{tabular}{|c|c|c|c|}
\hline 2 & $\begin{array}{l}\text { Transfer } \\
\text { Jawa-Bali }\end{array}$ & $\begin{array}{l}223,943 \\
\text { MW }\end{array}$ & $\begin{array}{l}\text { Swing } \\
\text { (Kabel } \\
\text { laut) }\end{array}$ \\
\hline 3 & Total Daya & $\begin{array}{l}771,443 \\
\mathrm{MW}\end{array}$ & \\
\hline 4 & $\begin{array}{l}\text { Rugi Daya } \\
\text { total }\end{array}$ & $\begin{array}{l}27,590 \\
\mathrm{MW}\end{array}$ & $\begin{array}{l}3,58 \% \text { dari } \\
\text { total suplai }\end{array}$ \\
\hline 5 & $\begin{array}{l}\text { Tegangan } \\
\text { tertinggi }\end{array}$ & $\begin{array}{l}150,67 \\
\mathrm{kV}\end{array}$ & $\begin{array}{l}\text { GI } \\
\text { Amlapura }\end{array}$ \\
\hline 6 & $\begin{array}{l}\text { Tegangan } \\
\text { terendah }\end{array}$ & $\begin{array}{l}147,94 \\
\mathrm{kV}\end{array}$ & $\begin{array}{l}\text { GI } \\
\text { Payangan }\end{array}$ \\
\hline 7 & $\begin{array}{l}\text { Rugi Daya } \\
\text { terbesar }\end{array}$ & $\begin{array}{l}3,133 \\
\text { MW }\end{array}$ & $\begin{array}{c}\text { Penghantar } \\
\text { Kapal- } \\
\text { Baturiti } \\
\end{array}$ \\
\hline 8 & $\begin{array}{l}\text { Pembebanan } \\
\text { arus terbesar } \\
\text { penghantar }\end{array}$ & $388 \mathrm{~A}$ & $\begin{array}{c}\text { Gilimanuk- } \\
\text { Negara1\&2 } \\
(60,16 \%) \\
\end{array}$ \\
\hline
\end{tabular}

\subsection{Hasil Analisis Aliran Daya dan Rugi Daya Skenario 2}

Pada skenario 2 bulan Desember 2014 terjadi pengurangan kapasitas pembangkit di Pesanggaran sebesar 90 MW dari total sebesar 337,5 MW menjadi 247,5 MW. Pengurangan pembangkitan di pusat beban akan merubah aliran daya, tegangan dan rugi-rugi pada penghantar. 
Tabel 2. Rangkuman Hasil Analisis Aliran Daya dan Rugi Daya Skenario 2

\begin{tabular}{|c|c|c|c|}
\hline No & Uraian & Nilai & Keterangan \\
\hline 1 & $\begin{array}{l}\text { Pembangkitan } \\
\text { Bali }\end{array}$ & 457,50 MW & \\
\hline 2 & $\begin{array}{l}\text { Transfer } \\
\text { Jawa-Bali }\end{array}$ & $\begin{array}{l}331,462 \\
\text { MW }\end{array}$ & $\begin{array}{l}\text { Swing } \\
\text { (Kabel laut) }\end{array}$ \\
\hline 3 & Total Daya & $\begin{array}{l}788,962 \\
\text { MW }\end{array}$ & \\
\hline 4 & $\begin{array}{l}\text { Rugi Daya } \\
\text { total }\end{array}$ & 46,340 MW & $\begin{array}{l}5,87 \% \text { dari } \\
\text { total suplai }\end{array}$ \\
\hline 5 & $\begin{array}{l}\text { Tegangan } \\
\text { tertinggi }\end{array}$ & $150,54 \mathrm{kV}$ & GI Amlapura \\
\hline 6 & $\begin{array}{l}\text { Tegangan } \\
\text { terendah }\end{array}$ & $147,64 \mathrm{kV}$ & GI Payangan \\
\hline 7 & $\begin{array}{l}\text { Rugi Daya } \\
\text { terbesar }\end{array}$ & 5,272 MW & $\begin{array}{l}\text { Penghantar } \\
\text { Kapal- } \\
\text { Baturiti }\end{array}$ \\
\hline 8 & $\begin{array}{l}\text { Pembebanan } \\
\text { arus terbesar } \\
\text { penghantar }\end{array}$ & $499,9 \mathrm{~A}$ & $\begin{array}{l}\text { Gilimanuk- } \\
\text { Negara } 1 \text { dan } \\
2(77,50 \%)\end{array}$ \\
\hline
\end{tabular}

\subsection{Hasil Analisis Aliran Daya dan Rugi Daya Skenario 3}

Pada skenario 3 tahun 2015 terjadi penambahan kapasitas pembangkit di Pesanggaran sebesar $120 \mathrm{MW}$ dari total sebesar 247,5 MW menjadi 367,5 MW, sedangkan untuk beban menggunakan beban puncak tahun 2014. Penambahan pembangkitan di pusat beban akan merubah aliran daya, tegangan, dan rugi-rugi pada penghantar.

Tabel 3. Rangkuman Hasil Analisis Aliran Daya dan Rugi Daya Skenario 3

\begin{tabular}{|l|l|l|l|}
\hline No & Uraian & Nilai & Keterangan \\
\hline 1 & $\begin{array}{l}\text { Pembangkit } \\
\text { an Bali }\end{array}$ & $577,50 \mathrm{MW}$ & \\
\hline 2 & $\begin{array}{l}\text { Transfer } \\
\text { Jawa-Bali }\end{array}$ & $189,359 \mathrm{MW}$ & $\begin{array}{l}\text { Swing } \\
\text { (Kabel laut) }\end{array}$ \\
\hline 3 & Total Daya & $766,859 \mathrm{MW}$ & \\
\hline 4 & $\begin{array}{l}\text { Rugi Daya } \\
\text { total }\end{array}$ & $22,672 \mathrm{MW}$ & $\begin{array}{l}2,96 \% \text { dari } \\
\text { total suplai }\end{array}$ \\
\hline 5 & $\begin{array}{l}\text { Tegangan } \\
\text { tertinggi }\end{array}$ & $150,71 \mathrm{kV}$ & GI Amlapura \\
\hline 6 & $\begin{array}{l}\text { Tegangan } \\
\text { terendah }\end{array}$ & $148,02 \mathrm{kV}$ & GI Payangan \\
\hline 7 & $\begin{array}{l}\text { Rugi Daya } \\
\text { terbesar }\end{array}$ & $2,551 \mathrm{MW}$ & $\begin{array}{l}\text { Penghantar } \\
\text { Kapal- } \\
\text { Baturiti }\end{array}$ \\
\hline 8 & $\begin{array}{l}\text { Pembebanan } \\
\text { arus terbesar } \\
\text { penghantar }\end{array}$ & $351,5 \mathrm{~A}$ & $\begin{array}{l}\text { Gilimanuk- } \\
\text { Negara 1\&2 } \\
\text { (54,50\%) }\end{array}$ \\
\hline
\end{tabular}

\subsection{Hasil Analisis Aliran Daya dan Rugi Daya Skenario 4}

Pada skenario 4 adalah skenario 3 dengan memakai beban puncak prediksi tahun 2015 sebesar 861 A sesuai RUPTL 2013-2022 [5]. Perubahan beban juga akan mempengaruhi aliran daya, tegangan, dan rugi-rugi pada penghantar.

Tabel 4. Rangkuman Hasil Analisis Aliran Daya dan Rugi Daya Skenario 4

\begin{tabular}{|l|l|l|l|}
\hline No & Uraian & Nilai & Keterangan \\
\hline 1 & $\begin{array}{l}\text { Pembangkitan } \\
\text { Bali }\end{array}$ & $577,500 \mathrm{MW}$ & \\
\hline 2 & $\begin{array}{l}\text { Transfer } \\
\text { Jawa-Bali }\end{array}$ & $316,652 \mathrm{MW}$ & $\begin{array}{l}\text { Swing (Kabel } \\
\text { laut) }\end{array}$ \\
\hline 3 & Total Daya & $894,151 \mathrm{MW}$ & \\
\hline 4 & $\begin{array}{l}\text { Rugi Daya } \\
\text { total }\end{array}$ & $41,995 \mathrm{MW}$ & $\begin{array}{l}4,33 \% \text { dari total } \\
\text { suplai }\end{array}$ \\
\hline 5 & $\begin{array}{l}\text { Tegangan } \\
\text { tertinggi }\end{array}$ & $150,36 \mathrm{kV}$ & GI Amlapura \\
\hline 6 & $\begin{array}{l}\text { Tegangan } \\
\text { terendah }\end{array}$ & $147,59 \mathrm{kV}$ & GI Payangan \\
\hline 7 & $\begin{array}{l}\text { Rugi Daya } \\
\text { terbesar }\end{array}$ & $4,486 \mathrm{MW}$ & $\begin{array}{l}\text { Penghantar } \\
\text { Kapal-Baturiti }\end{array}$ \\
\hline 8 & $\begin{array}{l}\text { Pembebanan } \\
\text { arus terbesar } \\
\text { penghantar }\end{array}$ & $477,9 \mathrm{~A}$ & $\begin{array}{l}\text { Gilimanuk- } \\
\text { Negara 1\&2 } \\
(74,09 \%)\end{array}$ \\
\hline
\end{tabular}

\subsection{Hasil Analisis Aliran Daya dan Rugi Daya Skenario 5}

Skenario 5 adalah skenario 4 dengan penambahan asumsi PLTU Celukan Bawang beroperasi sebesar $130 \mathrm{MW}$ pada sistem kelistrikan Bali. Penambahan pembangkit tersebut akan mempengaruhi aliran daya, tegangan, dan rugi-rugi pada penghantar.

Tabel 5. Rangkuman Hasil Analisis Aliran Daya dan Rugi Daya Skenario 5

\begin{tabular}{|c|c|c|c|}
\hline No & Uraian & Nilai & Keterangan \\
\hline 1 & $\begin{array}{l}\text { Pembangkitan } \\
\text { Bali }\end{array}$ & 707,50 MW & \\
\hline 2 & $\begin{array}{l}\text { Transfer } \\
\text { Jawa-Bali }\end{array}$ & $183,470 \mathrm{MW}$ & $\begin{array}{l}\text { Swing (Kabel } \\
\text { laut) }\end{array}$ \\
\hline 3 & Total Daya & $890,970 \mathrm{MW}$ & \\
\hline 4 & $\begin{array}{l}\text { Rugi Daya } \\
\text { total }\end{array}$ & $38,574 \mathrm{MW}$ & $\begin{array}{l}4,33 \% \text { dari total } \\
\text { suplai }\end{array}$ \\
\hline 5 & $\begin{array}{l}\text { Tegangan } \\
\text { tertinggi }\end{array}$ & $151,70 \mathrm{kV}$ & $\begin{array}{l}\text { GI Celukan } \\
\text { Bawang }\end{array}$ \\
\hline 6 & $\begin{array}{l}\text { Tegangan } \\
\text { terendah }\end{array}$ & $147,60 \mathrm{kV}$ & GI Payangan \\
\hline 7 & $\begin{array}{l}\text { Rugi Daya } \\
\text { terbesar }\end{array}$ & 5,421 MW & $\begin{array}{l}\text { Penghantar } \\
\text { Kapal-Baturiti }\end{array}$ \\
\hline 8 & $\begin{array}{l}\text { Pembebanan } \\
\text { arus terbesar } \\
\text { penghantar }\end{array}$ & $525,9 \mathrm{~A}$ & $\begin{array}{l}\text { Celukan Bawang } \\
\text { Pemaron } \\
(19,26 \%)\end{array}$ \\
\hline
\end{tabular}




\subsection{Analisis Rugi Daya Skenario Perubahan Kapasitas Pembangkit di Pesanggaran}

Skenario $1 \mathrm{~s} / \mathrm{d} 3$ digunakan untuk membandingkan rugi daya dan energi sistem kelistrikan Bali akibat perubahan kapasitas pembangkitan di Pesanggaran dengan sistem jaringan kelistrikan dan beban puncak yang sama. Sedangkan skenario 4 dan 5 untuk membandingkan rugi daya dan energi pada sistem kelistrikan Bali pada tahun 2015 saat PLTU Celukan Bawang beroperasi 1 blok sebesar $130 \mathrm{MW}$.

Dari hasil rangkuman analisis aliran daya dan rugi daya pada skenario $1 \mathrm{~s} / \mathrm{d} 3$ menunjukkan bahwa rugi daya tertinggi sistem kelistrikan Bali berada pada skenario 2 sebesar 46,34 MW sedangkan terendah pada skenario 3 yaitu sebesar 22,67 MW. Perbedaan yang paling signifikan antara skenario 2 dan 3 yaitu letak pembangkitan dengan pusat beban. Pada skenario 2 kapasitas pembangkit Pesanggaran lebih kecil dan suplai kabel laut 1 s/d 4 lebih besar dibanding skenario 3 . Pembangkit Pesanggaran merupakan pembangkit yang berada di pusat beban, sedangkan kabel laut $1 \mathrm{~s} / \mathrm{d} 4$ merupakan titik interkoneksi jaringan listrik dari Jawa ke Bali yang letaknya jauh dari pusat beban. Panjang jarak penghantar serta besarnya arus yang melewati penghantar tersebut, mengakibatkan rugi daya yang cukup besar [6]

Persamaan untuk rugi daya penghantar adalah arus yang dikuadratkan dikalikan dengan tahanan penghantar. Dalam persamaan tersebut arus sangat dominan mempengaruhi rugi daya yang terjadi pada penghantar. Jadi semakin besar arus mengalir serta semakin panjang jarak dari pembangkitan ke pusat beban maka semakin besar pula total rugi daya yang ditimbulkannya.

Dari hasil rangkuman analisis aliran daya dan rugi daya pada skenario 4 dan 5 menunjukkan bahwa beroperasinya PLTU Celukan Bawang sebesar 130 MW pada tahun 2015 memberikan dampak penurunan rugi daya pada sistem kelistrikan Bali.

\subsection{Rugi Energi Tahunan Sistem Kelistrikan Bali Sesuai Skenario $1 \mathrm{~s} / \mathrm{d} 5$}

Untuk menentukan rugi energi terlebih dahulu harus mengetahui parameter rugi daya dan loss factor yang terjadi dalam sistem kelistrikan Bali. Perkalian terhadap rugi daya dengan loss factor dan jumlah jam per tahun, akan mendapatkan rugi energi yang terjadi selama kurun waktu satu tahun. Dalam analisis nilai loss factor diasumsikan tetap setiap tahun pada masing masing skenario dan pengambilan beban untuk data sample tertanggal 10 Nopember s/d 16 Nopember 2014.

Tabel 6. Susut Energi Tahunan Sistem Kelistrikan Bali Sesuai Skenario $1 \mathrm{~s} / \mathrm{d} 5$

\begin{tabular}{|c|c|c|c|}
\hline No & Uraian & $\begin{array}{c}\text { Rugi Daya Saat } \\
\text { Beban } \\
\text { Puncak (MW) }\end{array}$ & $\begin{array}{c}\text { Susut Energi } \\
\text { Tahunan } \\
(\mathrm{GWh})\end{array}$ \\
\hline 1 & Skenario 1 & 27,590 & 178,849 \\
\hline 2 & Skenario 2 & 46,340 & 300,394 \\
\hline
\end{tabular}

\begin{tabular}{|l|l|l|l|}
\hline 3 & Skenario 3 & 22,672 & 146,969 \\
\hline 4 & Skenario 4 & 41,995 & 272,228 \\
\hline 5 & Skenario 5 & 38,574 & 250,052 \\
\hline
\end{tabular}

Rugi energi sangat dipengaruhi oleh rugi daya yang terjadi pada masing masing skenario. Semakin besar rugi daya yang terjadi maka rugi energi yang dihasilkan juga semakin besar. Dalam analisis perhitungan susut energi yang terjadi pada sistem kelistrikan Bali diperoleh skenario 2 menghasilkan rugi energi yang paling besar dibandingkan dengan skenario lainnya dikarenakan memiliki rugi daya terbesar.

\section{KESIMPULAN}

Beberapa hal yang dapat disimpulkan dari pembahasan di atas adalah sebagai berikut:

1. Pada Skenario $1 \mathrm{~s} / \mathrm{d} 3$ membuktikan bahwa pengurangan pembangkit pada pusat beban akan dapat memperbesar rugi daya, rugi energi dan susut tegangan, sebaliknya penambahan pembangkit pada pusat beban akan memperkecil rugi daya, rugi energi dan susut tegangan.

2. Skenario 4 dan 5 menunjukkan bahwa beroperasinya PLTU Celukan Bawang sebesar 130 MW pada tahun 2015 memberikan dampak penurunan rugi daya dan energi pada sistem kelistrikan Bali.

\section{DAFTAR PUSTAKA}

[1] Cekdin, C. 2006. Sistem Tenaga Listrik. Yogyakarta : ANDI Yogyakarta.

[2] Stevenson, William D, Jr. 1996. Analisa Sistem Tenaga Listrik. Jakarta : PT. Erlangga.

[3] Program Studi Magister Teknik Elektro. Laporan Kajian Pembangunan SUTET $500 \mathrm{kV}$ di Bali, Denpasar: Universitas Udayana: 2011

[4] Buller F.H, Woodrow C.A. 1928. Load Factor - Equivalent Hours Values Compared. Electrical World.

[5] PT PLN (Persero). RUPTL PT PLN (Persero) 2013-2022. Jakarta: PT PLN (Persero), 2013, halaman 469.

[6] Gina, Juniastra. W.G. Ariastina, I W. Sukerayasa, Analisis Susut Energi pada Sistem Kelistrikan Bali Sesuai Rencana Operasi SUTET $500 \mathrm{kV}$. Jurnal Teknik Elektro, 2012, Volume 11 No.1, Halaman 5. 